\title{
Spontaneous bruising in an elderly woman
}

\author{
Anand V Reddy, Karoline Chan, John I W Jones, Michael Vassallo, Martin Auger
}

A 75-year-old widow who lived alone with little social support was admitted to hospital after she was found by neighbours collapsed. She denied any medical history of note. There was no history of alcohol abuse and she was a lifetime non-smoker. Temperature on admission was $34.9^{\circ} \mathrm{C}$ rectal. She was noted to have extensive bruising over her legs and had spontaneous bleeding from her gums which were also noted to be abnormal (figure 1). Her weight on admission was $44.7 \mathrm{~kg}$, height $148 \mathrm{~cm}$, and body mass index (BMI) 21. The remainder of the physical examination was unremarkable and neurologically she was intact.

Initial investigations included a haemoglobin of $8.9 \mathrm{~g} / \mathrm{dl}$ and a normal white blood count, platelets, and mean corpuscular volume. A blood film showed schistocytes, a few hypersegmented neutrophils and burr cells. Erythrocyte sedimentation rate was $10 \mathrm{~mm}$ first hour, bilirubin 38 $\mu \mathrm{mol} / \mathrm{l}$ (normal < 18), total protein $69 \mathrm{~g} / \mathrm{dl}$, albumin $39 \mathrm{~g} / \mathrm{dl}$, alkaline phosphatase $157 \mathrm{IU} / \mathrm{l}$, gamma glutamyl aminotransferase $9 \mathrm{IU} / \mathrm{l}$, alanine aminotransferase $8 \mathrm{IU} / \mathrm{l}$, sodium $141 \mathrm{mmol} / \mathrm{l}$, potassium $4.3 \mathrm{mmol} / 1$, urea $22 \mathrm{mmol} / 1$, creatinine $133 \mu \mathrm{mol} / 1$. Other initial investigations included normal thyroid function, glucose, amylase, calcium, auto-antibody screen, protein strip, serum vitamin $B_{12}$ and serum ferritin. Her serum folate was $0.8 \mu \mathrm{g} / \mathrm{l}(1.7-13.0)$, red cell folate $86 \mu \mathrm{g} / / \mathrm{l}$ (85-500), fibrinogen $2.5 \mathrm{~g} / 1$ (1.5-4.0), thrombin time $13 \mathrm{~s} \mathrm{(12-16),} \mathrm{prothrombin} \mathrm{time} 18 \mathrm{~s}(10$ 14), activated partial thromboplastin time (APTT) 27 s (26-40). A chest X-ray showed a retrocardiac shadow due to a hiatus hernia. A gastroscopy showed a sliding hiatus hernia, erosive gastritis and duodenitis CLO test negative. Biopsy showed a mild chronic gastritis.

Two days after admission she was noted to have developed further swelling in both lower limbs with a deterioration in her bruising (figure 2). Her haemoglobin subsequently dropped to $6.8 \mathrm{~g} / \mathrm{dl}$ and her bilirubin rose to $70 \mu \mathrm{mol} / 1$, the rest of her liver function tests being normal. Her urea, creatinine and international normalised ratio (INR) corrected promptly with fluid replacement and oral vitamin $\mathrm{K}$ but her spontaneous bleeding persisted.

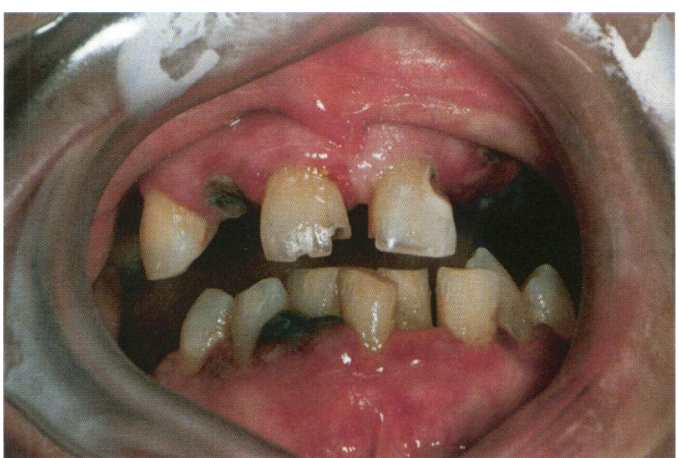

Figure 1

Department of

Medicine,

King's Mill Centre, Mansfield Road,

Sutton-in-Ashfield, Notts NG17 4JL, UK A V Reddy

K Chan

J I W Jones

M Vassallo

M Auger

Correspondence to Dr M Vassallo

Accepted 20 August 1997

\section{Questions}

1 What is the differential diagnosis of her spontaneous bleeding?

2 What additional test would be required to prove the diagnosis and how would you treat it?

3 What is the aetiology of the folate deficiency?

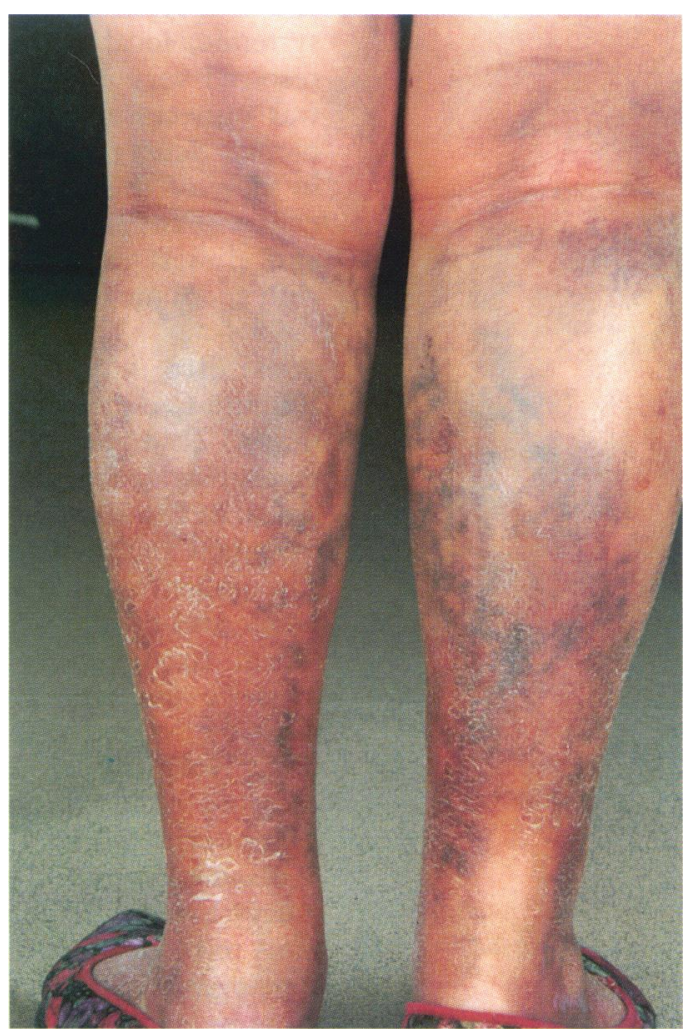

Figure 2 


\section{Answers}

QUESTION 1

The clinical evidence of spontaneous haemorrhage accompanied by a drop in her haemoglobin and a non-conclusive gastroscopy gave ample evidence that intramuscular haemorrhage was the cause of this patient's worsening anaemia. The hyperbilirubinaemia with normal liver function was due to resorption of the extravasated blood. There were no features of intravascular haemolysis to account for it.

Abnormalities of haemostasis can result in spontaneous bleeding. The normal platelet count excluded quantitative disorders such as idiopathic and thrombotic thrombocytopenic purpura. Congenital abnormalities of platelet function were unlikely since there was no history of bleeding. Myeloproliferative disease dysproteinaemia, uraemia and liver disease were excluded as causes of an acquired platelet dysfunction. The patient denied taking any drugs including alcohol or aspirin that can inhibit platelet function.

The prolonged prothrombin time suggested there was an acquired defect in coagulation. Its prompt correction and the normal INR two days after administering oral vitamin $K$ and the normal APTT suggested this defect was due to vitamin $\mathrm{K}$ deficiency.

Vascular abnormalities, both congenital and acquired, constitute the final group of possible causes for this patient's spontaneous bleeding. The patient's age at onset and clinical manifestations rule out connective tissue disorders like Ehler-Danlos, pseudoxanthoma elasticum or Osler Weber Rendu syndrome. Amyloid is an acquired cause of vascular fragility. There are at least five types of amyloid; primary, secondary, systemic, local and senile ${ }^{1}$. Since symptoms resolved very quickly on starting treatment it was unnecessary to do a rectal or a gingival biopsy. Scurvy was considered as a possibility in view of the patient's poor dietary history, concomitant folate and vitamin $\mathrm{K}$ deficiency and clinical evidence of gingival hyperplasia with spontaneous bleeding.

\section{QUESTION 2}

Vitamin C deficiency is diagnosed by the vitamin C (ascorbic acid) saturation test or by measuring leucocyte or serum ascorbic acid levels. In the first of these the patient is starved overnight and then given $700 \mathrm{mg}$ of vitamin C. The patient is then starved for a further four hours and all the urine is collected from the fourth to the sixth hour after ingestion to measure the total vitamin $\mathrm{C}$ excreted. This must be assayed within 30 minutes of collection. Normally at least $50 \mathrm{mg}$ should be excreted in the two-hour collection period. Our patient excreted $10.4 \mathrm{mg}$.

Plasma vitamin $C$ is nearly zero in manifest scurvy but the range in healthy subjects is too great to be of value for early diagnosis. Leucocyte levels of vitamin $C$ of less than $0.1 \mathrm{mg} / 100$ $\mathrm{ml}$ is indicative of deficiency. Since leucocyte levels reflect total body stores, Sauberlich ${ }^{2}$ suggested that it should be the preferred diagnostic test for scurvy. However, Thomas et al showed that the test may not identify all patients shown to be deficient with an oral vitamin $C$ saturation test, suggesting that the latter test is still useful in the diagnosis of scurvy.

In adult scurvy, ascorbic acid $250 \mathrm{mg}$ qid should be given until signs have disappeared. Other nutritional deficiencies should be treated.

\section{QUESTION 3}

Folic acid deficiency can occur in scurvy due to lack of protection of folate co-enzymes that maintain body folate in the reduced active state; the exact mechanism is not clear. Reduced dietary intake may also play a part in the pathogenesis of folate deficiency.

Anaemia associated with scurvy is common and may be normo-, micro- or macrocytic. Anaemia may present megaloblastic changes relating to the folate deficiency. ${ }^{4}$ In our patient, the hypersegmented neutrophils and the schistocytes suggested folic acid deficiency.

\section{Discussion}

The human body is unable to synthesise vitamin $C$ and a diet deficient in vitamin $C$ leads to scurvy. The clinical features of scurvy in adults differ from those in children. Today, adult scurvy is most common amongst elderly people living alone preparing their own food, ${ }^{5}$ and those with particular food fads. ${ }^{6}$ Alcoholism, smoking, acute illness, and gastrointestinal disease have been reported as predisposing to scurvy. ${ }^{78}$ Despite having an adequate calorific intake as judged by the normal BMI and protein and albumin levels, on closer questioning it became apparent that she lived on a diet of canned food and very little fresh fruit and vegetables.

Vitamin C is a co-factor in the synthesis of collagen and deficiency leads to the breakdown of connective tissue in and around the blood vessels, hence the bleeding tendency due to capillary fragility. Early symptoms are weakness and aching joints, muscles and bones. Keratosis of the hair follicles occurs with surrounding haemorrhage, and hairs acquire a typical corkscrew appearance. In advanced deficiency, ecchymosis is common. Purpura and spontaneous haemorrhage into muscles, joints and under nails can occur. Gum changes occur in relation to natural teeth or hidden roots and consist of swelling, congestion and spongy degeneration with bleeding. Secondary infection, gangrene, and loosening of the teeth eventually supervene. Anaemia is common and the aetiology is multifactorial due to tissue haemorrhage, concomitant folate and iron deficiency, gastrointestinal blood loss and intravascular haemolysis. Sudden death can occur. ${ }^{4}$

Scurvy may mimic disorders like vasculitis, systemic bleeding disorders and deep vein thrombosis. ${ }^{9}$ A high index of suspicion of this disorder would avoid subjecting patients to unnecessary investigation and medications. A detailed nutritional assessment should form an integral part of the evaluation of patients, 
especially if they have risk factors for this disorder. ${ }^{10}$ Prognosis is excellent and clinical improvement is usually apparent soon after commencing on vitamin $\mathrm{C}$. Haemorrhage ceases and blood regeneration begins almost immediately. Our patient's abnormal vitamin C saturation test and the prompt resolution of her abnormal clinical signs after administering ascorbic acid, as well as multivitamin replacement and the lack of other treatment, points to scurvy as the cause of the patient's symptoms. Typically, vitamin C deficiency is not isolated; other nutritional deficiencies should be sought in newly diagnosed cases of scurvy and a failure

1 Anon. Case records of the Massachusetts General Hospital weekly clinico-pathological exercises. Case 39. A 72 year old man with exertional dyspnoea fatigue and extensive ecchymosis and purpuric lesions [clinical conference]. $N$ Engl F Med 1995;333:1695-702.

2 Sauberlich HE. Vitamin C status: methods and findings. Ann NY Acad Sci 1975;258:438-9.

3 Thomas AJ, Briggs RS, Monro P. Is leucocyte ascorbic acid an unreliable estimate of vitamin C deficiency? Age Ageing 1984;13:243-7.

4 Hoffbrand AV. Megaloblastic anaemia and miscellaneous deficiency anaemias. In: Weatherall DJ, Ledingham JGG, Warrell DA, eds, Oxford textbook of medicine, 3rd edn Oxford: Oxford University Press, 1996; p 3498.

5 Reuler JB, Broudy VC, Cooney TG. Adult scurvy. FAMA 1985;253:805-7.

6 Gil Llano JR, Grespo Rincon L, Ruiz Llano FC, Costo Campoamor A, Mateos Polo L, Gonzales MA. Scurvy: a serious and rare form of avitaminosis, easily diagnosed and treated. Presentation of a case. Anal Med Interna 1995;12 $450-2$. to improve rapidly after commencing vitamin replacement should prompt a search for underlying disease, especially gastrointestinal. ${ }^{11}$ Prophylaxis and provision of adequate social and nutritional support are other important aspects of treatment that must not be ignored.

\section{Final diagnosis}

Scurvy associated with multiple vitamin deficiency.

Keywords: scurvy; nutrition; elderly; vitamin deficiency

7 Hurlimann R, Solomon F. Scurvy - a mistakenly forgotten disease. Schweiz Med Wochenschr 1994;124:1373-80.

8 Sussewell HL, Wagner RF, Rosenbaum MT. Rectal carcinoma in a scorbutic patient. South Med 7 1984;77: 1215-6.

9 Mehta CL, Cripps D, Bridges AJ. Systemic pseudovasculitis from scurvy in anorexia nervosa. Arthrit Rheum 1996;39: 532-3.

10 Bistrian BR, Blackburn GL, Vitale J, Cochran D, Naylor J. Prevalence of malnutrition in general medical patients. FAMA 1976;235:1567-70.

11 Statters DJ, Asokan VS, Littlewood SM, Snape J. Carcinoma of the caecum in a scorbutic patient. Br $\mathcal{f}$ Clin Pract 1990;44:738-40. 